\title{
HOLISTIC CARE FOR LEPROSY PATIENTS IN LEMBATA DISTRICT, EAST NUSA TENGGARA
}

\author{
Pius Weraman \\ Faculty of Public Health, Nusa Cendana University, Kupang \\ Nusa Cendana University, Kupang
}

\begin{abstract}
Background: Lembata is a district in East Nusa Tenggara with various infectious and non-infectious diseases, including leprosy. The monthly incidence of leprosy increase by 1-2 new cases of leprosy per village. In Lembata there is Lembata Damian Hospital, a leprosy hospital established in 1959. Lembata District has a population of 157,265 people, most of than have low education level. The local government implemented a new approach of leprosy treatment emphasizing holistic treatment including medical, psychological, social, and spiritual treatment with the objective to cure and to improve the quality of life of leprosy patients. This study aimed to assess the effectiveness of the holistic leprosy treatment in Lembata District, East Nusa Tenggara.
\end{abstract}

Subjects and Method: This was a qualitative study with problem solving approach. The holistic treatment applied to leprosy patients consisted of some components. In order to develop immune system in the body, the patients received local food nutritional intake, including maize, tubers, papaya fruit and leaf, and kelor leaf. To heal ulcers and wounds, the patients received blended topical herbal treatment, consisting of local papaya leaf, kelor leaf, turmeric tuber, and salt. The psychological component of holistic treatment aimed to prevent stress, feeling of despair, feeling of isolation, and lack of self confidence. The social component of holistic treatment empowered patients to be accepted by the surrounding community members. The spiritual component of holistic treatment attempted to enhance motivation by practicing prayer. The holistic treatment was developed by Porat Antonius. The data were collected by in-depth interview and direct observation.

Results: As many as 76 cases of leprosy cases were identified through laboratory examination conducted at Damian hospital. As many as 33 leprosy cases received the holistic treatment in addition to anti-leprosy medical drugs. 19 of all 33 leprosy patients treated with the holistic treatment were cured. 14 patients refused to participate in the holistic treatment.

Conclusion: Delving in local wisdom, the holistic treatment in complementary with modern anti-leprosy drugs can be used to cure leprosy patients and to improve their quality of life. Further studies, however, need to be carried out to provide rigorous scientific evidence on the effectiveness of the holistic treatment.

Keywords: Leprosy, holistic treatment, herbal medicine, quality of life

Correspondence: Pius Weraman. Faculty of Public Health, Nusa Cendana University, Kupang. Email: piusweraman@yahoo.com.

Mobile: +628123789293 